\title{
Same Day Sub-tenon's Triamcinolone and Anti-VEGF Injections in Patients with Macular Edema Secondary to Central Retinal Vein Occlusion
}

\author{
Justin J. Yamanuha ${ }^{1^{*}}$, Carolyn R. Flock ${ }^{2}$ \\ ${ }^{1}$ Bascom Palmer Eye Institute, 900 NW 17th Street, Miami, FL 33136, United States \\ ${ }^{2}$ Research Operations, Mayo Clinic Health System La Crosse, 700 West Avenue South, La Crosse, WI 54601, \\ United States
}

"Corresponding Author: Dr. Justin J. Yamanuha, Bascom Palmer Eye Institute, 900 NW 17th Street, Miami, FL 33136, United States, E-mail: jxy136@med.miami.edu

Received: 31 October 2018; Accepted: 06 November 2018; Published: 20 November 2018

\begin{abstract}
Purpose: Sub-tenon's or suprachoroidal triamcinolone have been shown to effectively reduce macular edema and extend anti-vascular endothelial factor (anti-VEGF) interval in patients with macular edema from retinal vein occlusions $[1,2]$. This single site retrospective review was conducted to determine if this combination treatment could achieve similar benefits and also improve visual acuity in patients treated for central retinal vein occlusion (CRVO).

Methods: The Mayo Clinic Institutional Review Board (IRB) granted approval for the retrospective review of patients treated with simultaneous same day anti-VEGF and sub-tenon's triamcinolone acetonide injections for macular edema secondary to CRVO at the Mayo Clinic Health System in La Crosse, Wisconsin. Patients were excluded if the prior treatment history was unknown or if follow up did not occur after three months.
\end{abstract}

Primary Outcomes: Visual acuity, intraocular pressure, optical coherence tomography (OCT) thickness, and antiVEGF injection interval were analyzed at treatment day and three months. 
Results: Four patients treated with simultaneous same day anti-VEGF and sub-tenon's triamcinolone had reduction in OCT thickness and extended anti-VEGF interval at three months. Visual acuity improved by a mean of one line, but the degree of improvement was not proportional to the degree of OCT thickness reduction. Two of four patients required ongoing topical IOP lowering medications at three months.

Conclusions: Simultaneous same day anti-VEGF and sub-tenon's acetonide injections can reduce macular edema and permit lengthened injection interval. Future research is needed to determine if this combination treatment for CRVO associated macular edema can improve acuity if administered early in the treatment course.

Keywords: Anti-VEGF (bevacizumab, aflibercept); Central Retinal Vein Occlusion (CRVO); Combination antiVEGF and sub-tenon's triamcinolone; Sub-tenon's triamcinolone

\section{Summary Statement}

We present a case series of four patients treated for macular edema secondary to central retinal vein occlusion with same day anti-VEGF and sub-tenon's triamcinolone. All patients were able to have their injection interval extended with reduced OCT thickness but visual acuity did not improve in all patients.

\section{Introduction}

Treatment of macular edema associated with retinal vein occlusions has evolved from focal and grid laser to intravitreal anti-vascular endothelial growth factor (anti-VEGF) and corticosteroid injection therapy. The use of subtenon's or suprachoroidal triamcinolone has been shown to be an effective adjunctive treatment along with antiVEGF therapy for macular edema associated with retinal vein occlusions [1-2]. Most recently, the Tanzanite study [1] showed reduced injection frequency three months after simultaneous same day aflibercept and suprachoroidal triamcinolone acetonide in patients with macular edema secondary to retinal vein occlusion. Prior studies have also shown reduced ocular coherence tomography (OCT) thickness with these dual anti-VEGF and regional corticosteroid therapy, but not all have shown improved visual acuity. This single site retrospective review was conducted to determine if various anti-VEGF injections and sub-tenon's triamcinolone may achieve similar benefits and also improve visual acuity.

\section{Methods}

The Mayo Clinic Institutional Review Board (IRB) granted approval for the retrospective review of all patients treated in the Medical Retina clinic at the Mayo Clinic Health System La Crosse, Wisconsin over a two year period from 2016-2018 with simultaneous same day anti-VEGF and sub-tenon's triamcinolone acetonide injections for macular edema secondary to central retinal vein occlusion (CRVO). Patients were excluded if follow up did not occur after three months, if the duration of therapy or number of prior anti-VEGF injections was unknown, or if prior intraocular/regional corticosteroid, or if macular or pan-retinal photocoagulation laser was used in the treated eye. Data collected included age at time of dual therapy, number, duration and type of prior anti-VEGF therapy, 
Snellen visual acuity, intraocular pressure with any relevant topical medications, OCT central subfield thickness obtained via the Heidelberg Spectralis system on day of dual therapy, and current and subsequent anti-VEGF injection treatment interval.

\subsection{Baseline characteristics}

The duration of treatment of macular edema secondary to central retinal vein occlusion prior to same day dual therapy ranged from 13 to 40 months (mean 25 months) and the total prior number of anti-VEGF injections ranged from 21 to 33 (mean 21). No patient was treated with prior intraocular steroid, periocular steroid, or focal or panretinal photocoagulation laser therapy (Table 1).

\begin{tabular}{|l|l|l|l|l|l|l|}
\hline $\begin{array}{l}\text { Patient } \\
\text { number, } \\
\text { age, gender } \\
\text { eye }\end{array}$ & $\begin{array}{l}\text { Duration of } \\
\text { prior anti- } \\
\text { VEGF } \\
\text { monotherapy }\end{array}$ & $\begin{array}{l}\text { Number and } \\
\text { type of prior } \\
\text { ant-VEGF } \\
\text { Injection }\end{array}$ & $\begin{array}{l}\text { Interval prior to } \\
\text { same day dual } \\
\text { anti-VEGF and } \\
\text { sub-tenon's } \\
\text { triamcinolone }\end{array}$ & $\begin{array}{l}\text { Acuity } \\
\text { day of } \\
\text { combo } \\
\text { therapy }\end{array}$ & $\begin{array}{l}\text { IOP day of } \\
\text { dual } \\
\text { therapy } \\
\text { and IOP } \\
\text { drops }\end{array}$ & $\begin{array}{l}\text { OCT } \\
\text { central } \\
\text { subfield day } \\
\text { of dual } \\
\text { therapy }\end{array}$ \\
\hline $\begin{array}{l}\text { \#1-74 year } \\
\text { old male, } \\
\text { CRVO right }\end{array}$ & 13 months & 12 bevacizumab & $\begin{array}{l}\text { Q5 week } \\
\text { bevacizumab }\end{array}$ & $20 / 30$ & $10 \mathrm{mmHg}$ & 345 microns \\
\hline $\begin{array}{l}\text { \#2-66 year } \\
\text { old male, } \\
\text { CRVO left }\end{array}$ & 21 months & 15 bevacizumab & $\begin{array}{l}\text { Q5 week } \\
\text { bevacizumab }\end{array}$ & $20 / 80$ & $18 \mathrm{mmHg}$ & 633 microns \\
\hline $\begin{array}{l}\text { \#3-45 year } \\
\text { old male, } \\
\text { CRVO left }\end{array}$ & 27 months & $\begin{array}{l}6 \text { bevacizumab } \\
20 \text { aflibercept }\end{array}$ & $\begin{array}{l}\text { Q5 week } \\
\text { aflibercept }\end{array}$ & $20 / 30$ & $\begin{array}{l}16 \mathrm{mmHg} \\
\text { Timolol } \\
\text { daily, } \\
\text { Latanoprost } \\
\text { nightly }\end{array}$ & 388 microns \\
\hline $\begin{array}{l}\text { \#4-74 year } \\
\text { old male, } \\
\text { CRVO left }\end{array}$ & 40 months & $\begin{array}{l}2 \text { bevacizumab } \\
31 \text { aflibercept }\end{array}$ & $\begin{array}{l}\text { Q5 week } \\
\text { aflibercept }\end{array}$ & $20 / 80$ & 13 mmHg & 767 microns \\
\hline
\end{tabular}

Table 1: Baseline characteristics.

3.1.1 Injection Technique: All four patients were treated with same day simultaneous intravitreal anti-VEGF and sub-tenon's triamcinolone acetonide in the affected eye. After ensuring informed written consent was obtained, time out procedures were performed ensuring correct patient, medical record number, and treated eye. The eye was anesthetized with topical tetracaine $0.5 \%$ and sterilized with $5 \%$ betadine to the ocular surface and $10 \%$ betadine to the eyelids. A sterile speculum was placed in the eyelids and the patient was directed to look up and the opposite side. The anti-VEGF agent was injected 3.5-4 $\mathrm{mm}$ posterior to the inferotemporal limbus via a 32 gauge needle. Topical 5\% betadine was reapplied and sub-conjunctival $1 \%$ lidocaine without epinephrine was then administered over the superotemporal aspect of the globe. The speculum was removed to allow additional time for anesthesia. The triamcinolone acetonide- $20 \mathrm{mg} / 0.5 \mathrm{~mL}$ was withdrawn from the vial with an 18 gauge needle. A new speculum was applied to the eyelids and the patient was directed to look down and to the opposite side. The $20 \mathrm{mg} / 0.05 \mathrm{~mL}$ of subtenon's triamcinolone acetonide was then injected via a 30 gauge needle over the superotemporal aspect of the 
globe. Topical betadine was reapplied and the eye was irrigated with sterile balanced salt solution. One drop of topical moxifloxacin was applied to the treated eye and visual acuity was confirmed to be at least hand motion at the completion of the procedure. Any patients who were using topical medication for IOP lowering were asked to continue these medications and those who were not using such medications were asked to use topical brimonidine twice daily or dorzolamide $2 x /$ day and timolol $2 x /$ day in the treated eye.

3.1.2 Follow-Up: All patients returned at 4-6 weeks for IOP check and for the respective anti-VEGF injection in the treated eye based on the prior interval. At this visit, any patient who did not have elevated IOP from treatment day baseline had IOP medication discontinued. Follow up dilated examination with OCT was then performed 6-8 weeks later (three months from the date of dual anti-VEGF and sub-tenon's triamcinolone therapy).

The primary outcomes included changes in visual acuity, intraocular pressure, optical coherence tomography (OCT) central subfield thickness, and anti-VEGF injection interval on the day of combination therapy compared to three months after treatment. A total of six patients were treated with simultaneous same day anti-VEGF and sub-tenon's triamcinolone acetonide for CRVO associated macular edema. One patient was excluded as she was lost to follow up after her three month visit and another was excluded as outside records could not clearly quantify the duration and number of prior anti-VEGF injections. The four patients who met study criteria had data reported at three months.

\subsection{Three Month Results}

3.2.1 Visual acuity: Snellen visual acuity changes ranged from loss of one line to gain of four lines, with a mean of one line gained at three months following same day dual therapy with anti-VEGF and sub-tenon's triamcinolone (Table 2).

\begin{tabular}{|c|c|c|c|c|c|c|c|}
\hline $\begin{array}{l}\text { Patient } \\
\text { number, } \\
\text { age, } \\
\text { gender, } \\
\text { eye }\end{array}$ & $\begin{array}{l}\text { OCT } \\
\text { central } \\
\text { subfield } 3 \\
\text { months } \\
\text { after dual } \\
\text { therapy } \\
\text { (change } \\
\text { from day of } \\
\text { treatment) }\end{array}$ & $\begin{array}{l}\text { Change in } \\
\text { OCT } \\
\text { central } \\
\text { subfield at } \\
3 \text { months } \\
\text { vs day of } \\
\text { dual } \\
\text { therapy }\end{array}$ & $\begin{array}{l}\text { Interval } 3 \\
\text { months after } \\
\text { same day dual } \\
\text { anti-VEGF } \\
\text { and sub- } \\
\text { tenon's } \\
\text { triamcinolone }\end{array}$ & $\begin{array}{l}\text { Change in } \\
\text { anti- } \\
\text { VEGF } \\
\text { injection } \\
\text { interval vs } \\
\text { day of } \\
\text { dual } \\
\text { therapy }\end{array}$ & $\begin{array}{l}\text { Acuity } \\
\text { at } 3 \\
\text { months }\end{array}$ & $\begin{array}{l}\text { Change in } \\
\text { acuity at } 3 \\
\text { months vs } \\
\text { day of dual } \\
\text { therapy }\end{array}$ & $\begin{array}{l}\text { IOP at } 3 \\
\text { months after } \\
\text { dual therapy } \\
\text { and IOP } \\
\text { drops (change } \\
\text { from baseline) }\end{array}$ \\
\hline $\begin{array}{l}\# 1-74 \\
\text { year old } \\
\text { male, } \\
\text { CRVO } \\
\text { right }\end{array}$ & 339 microns & -6 microns & $\begin{array}{l}\text { Q8 week } \\
\text { bevacizumab }\end{array}$ & +3 weeks & $20 / 25$ & +1 line & $\begin{array}{l}15 \mathrm{mmHg}(+5 \\
\mathrm{mmHg})\end{array}$ \\
\hline $\begin{array}{l}\# 2-66 \\
\text { year old } \\
\text { male, } \\
\text { CRVO } \\
\text { left }\end{array}$ & 262 microns & $\begin{array}{l}-371 \\
\text { microns }\end{array}$ & $\begin{array}{l}\text { Q6 week } \\
\text { bevacizumab }\end{array}$ & +1 week & $20 / 40$ & +4 lines & $\begin{array}{l}22 \mathrm{mmHg}, \\
\text { resume } \\
\text { Timolol daily } \\
(+4 \mathrm{mmHg})\end{array}$ \\
\hline
\end{tabular}




\begin{tabular}{|l|l|l|l|l|l|l|l|}
\hline $\begin{array}{l}\text { \#3-45 } \\
\text { year old } \\
\text { male, } \\
\text { CRVO } \\
\text { left }\end{array}$ & 229 microns & $\begin{array}{l}-159 \\
\text { microns }\end{array}$ & $\begin{array}{l}\text { Q6 week } \\
\text { aflibercept }\end{array}$ & +1 week & $20 / 40$ & -1 line & $\begin{array}{l}\text { 25 mmHg } \\
\text { Timolol daily, } \\
\text { Latanoprost } \\
\text { nightly, add } \\
\text { Brimonidine } \\
\text { 2x/day (+9 } \\
\text { mmHg) }\end{array}$ \\
\hline $\begin{array}{l}\# 4-74 \\
\text { year old } \\
\text { male, } \\
\text { CRVO } \\
\text { left }\end{array}$ & 203 microns & $\begin{array}{l}-564 \\
\text { microns }\end{array}$ & $\begin{array}{l}\text { Q6 week } \\
\text { aflibercept }\end{array}$ & +1 week & $20 / 80$ & 0 lines & $\begin{array}{l}16 \mathrm{mmHg}(+3 \\
\mathrm{mmHg})\end{array}$ \\
\hline
\end{tabular}

Table 2: Dual therapy with anti-VEGF and sub-tenon's triamcinolone.

3.2.2 Intraocular pressure: All four patients (100\%) showed elevation of intraocular pressure at three months compared to day of dual therapy (range +3 to $+9 \mathrm{mmHg}$, mean $+5 \mathrm{mmHg}$ ). One of four was on prior topical IOP lowering medications and this patient was asked to use an additional medication at three months. A second patient stopped topical IOP lowering medication at 6 weeks, but was asked to resume timolol at 3 months.

3.2.3 OCT reduction: All four patients had reduction in OCT central subfield at 3 months with a range from -6 microns to -564 microns (mean -275 microns). The two patients with the thickest maculae on the day of dual therapy also had the most significant reduction in OCT central subfield thickness (Figure 1-4).
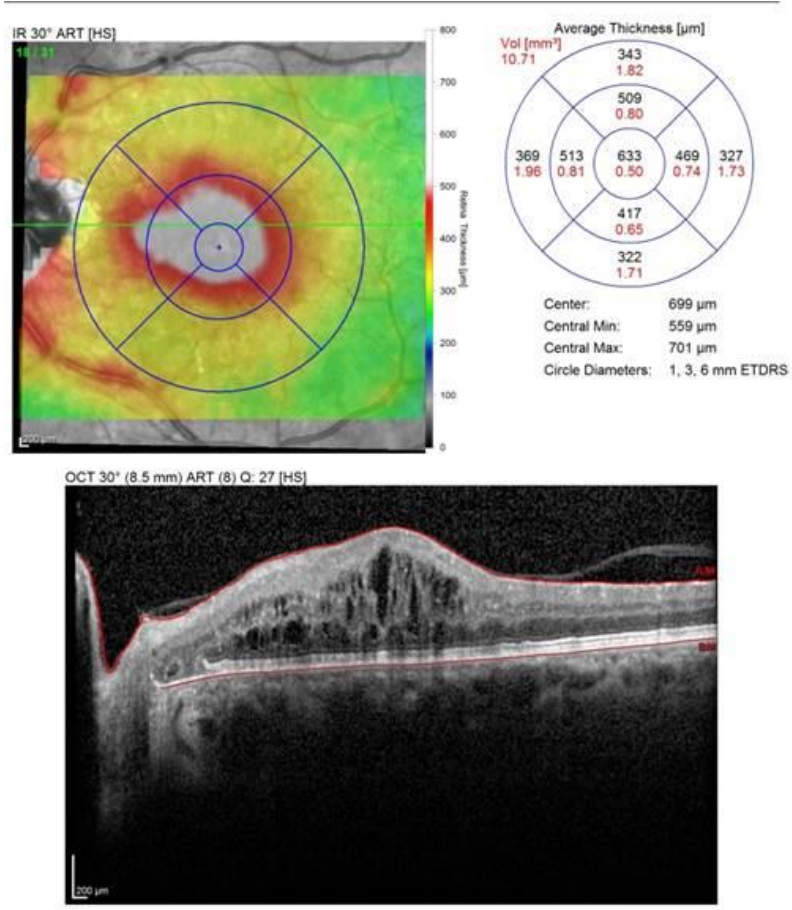

Figure 1: OCT for patient \#2 on day of simultaneous bevacizumab and posterior sub-tenon's triamcinolone. 

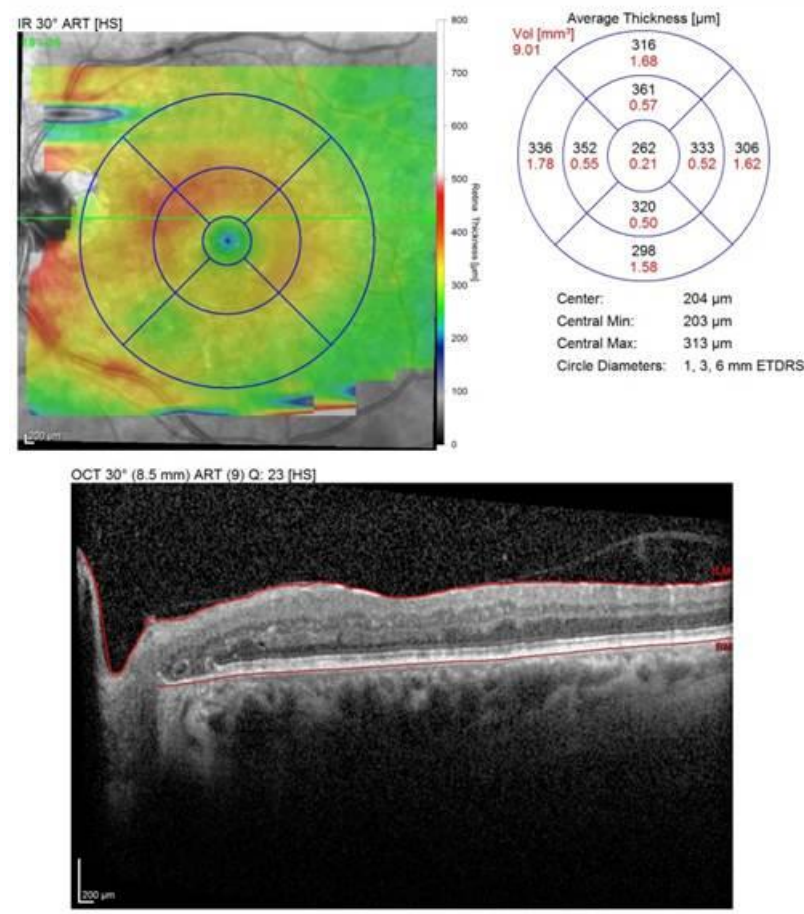

Figure 2: OCT for patient \#2 at three months after simultaneous bevacizumab and posterior sub-tenon's triamcinolone.
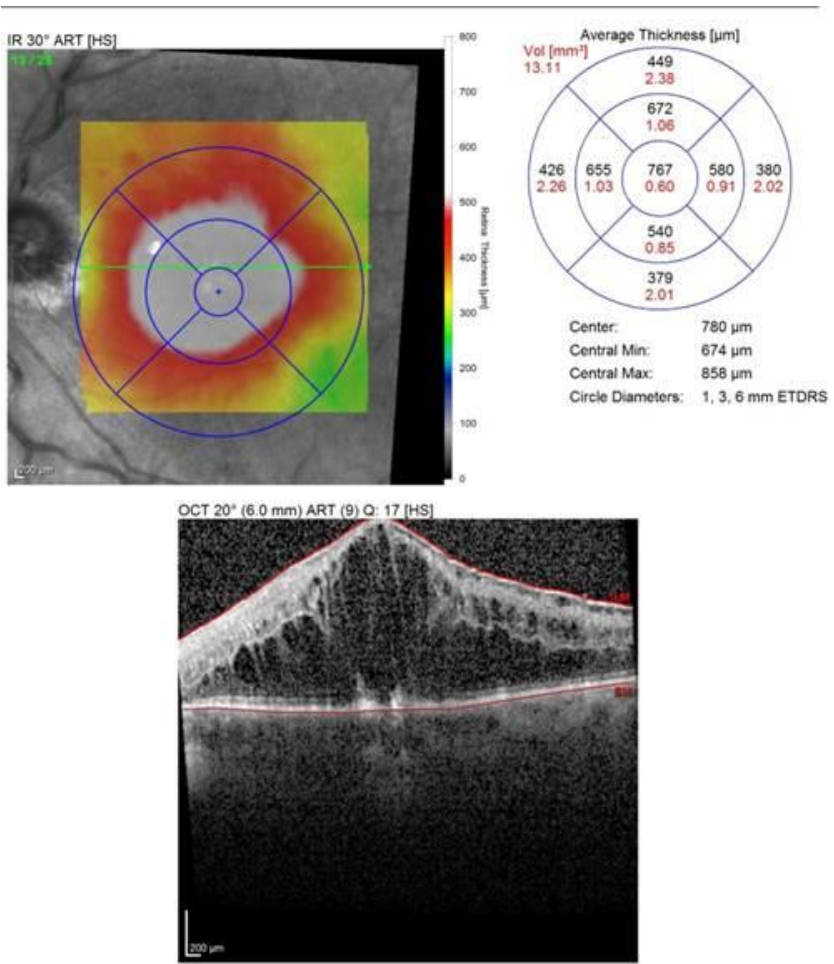

Figure 3: OCT for patient \#4 on day of simultaneous aflibercept and posterior sub-tenon's triamcinolone. 

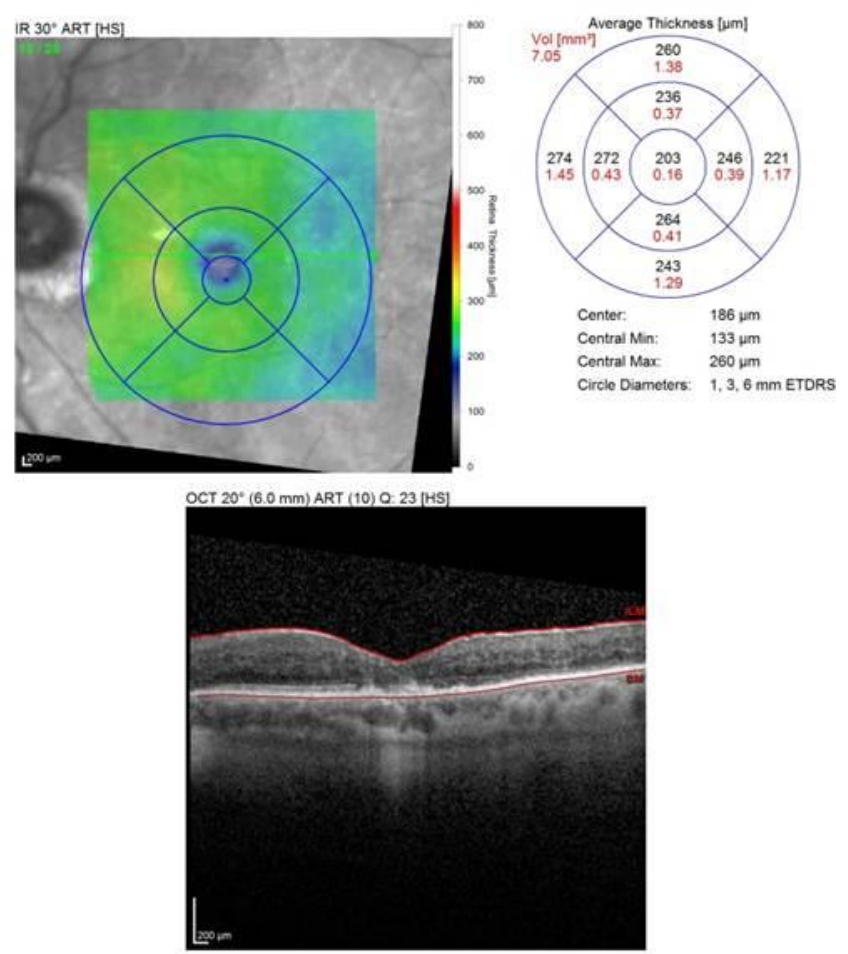

Figure 4: OCT for patient \#4 at three months after simultaneous aflibercept and posterior sub-tenon's triamcinolone.

3.2.4 Anti-VEGF injection interval: All four patients were able to have anti-VEGF interval extended at three months by at least one week (from every 5 weeks to every 6 weeks). One patient with baseline acuity of 20/30 and OCT central subfield of 345 microns, was extended from every five weeks to every eight weeks due to excellent functional and anatomic results.

\section{Discussion}

The BRAVO [3] and CRUISE [4] studies helped to establish safety and efficacy of the anti-VEGF ranibizumab versus sham injections in the treatment of macular edema secondary to branch retinal vein occlusions and central retinal vein occlusions, respectively. Roughly one year prior, the SCORE study [5] showed superiority of intravitreal triamcinolone vs observation in patients with central retinal vein occlusion and also demonstrated increased rates of elevated intraocular pressure in the $4 \mathrm{mg}$ versus the $1 \mathrm{mg}$ group.

The majority of patients with new onset macular edema secondary to retinal vein occlusions are started with antiVEGF injections as first line therapy, but there may still be a role for corticosteroids as a primary or adjunctive treatment with anti-VEGF monotherapy. Steroids reduce vascular permeability and also affect gene expression of inflammatory mediators [6], in addition to their ability to block VEGF. Sub-tenon's triamcinolone monotherapy has been shown to improve visual acuity at one month after administration for retinal vein occlusion, but has varying efficacy in regard to OCT thickness reduction [7-9]. These studies have shown rates of IOP elevation from 5\%-29\% 
of patients treated with posterior sub-tenon's triamcinolone monotherapy for macular edema secondary to retinal vein occlusion.

Recent studies have shown improved visual acuity with combination anti-VEGF aflibercept with suprachoroidal triamcinolone $^{1}$ as well as bevacizumab with posterior sub-tenon's triamcinolone [2]. This retrospective study included two patients on aflibercept and two patients on bevacizumab. All four patients received same day posterior sub-tenon's triamcinolone $20 \mathrm{mg} / 0.5 \mathrm{~mL}$ in addition to their respective anti-VEGF agent. This single study site was not powered to detect correlations or non-inferiority, or differences between anti-VEGF agents, but a few associations could be identified. Although mean visual acuity was one line gain, one patient lost one line, and one did not change, so this dual same day anti-VEGF and sub-tenon's triamcinolone therapy is not universally effective at improving visual acuity.

The most uniform result at three months was the ability to extend the anti-VEGF interval by a mean of 1.5 weeks. As it is the practice of this author to extend anti-VEGF treatment by one week until an eight week interval is maintained, others may have extended by two weeks at this similar point. There was no relationship with younger age, anti-VEGF type (bevacizumab versus aflibercept) nor baseline OCT central subfield thickness in terms of response to the dual same day anti-VEGF and sub-tenon's triamcinolone therapy in these four patients at three months. The patient with the most dramatic acuity gain did not have the most significant reduction in OCT thickness. Also, the patient with the most pronounced reduction of OCT central subfield thickness also had the thickest retina on the day of dual therapy but no change in Snellen acuity at three months. It might be presumed, then, that this patient had the most to gain in terms of OCT thickness reduction, but perhaps this patient's macula may have been limited by chronic edema.

The most significant consequence, elevated intraocular pressure, affected 50\% (two of four) patients, requiring one or more topical medications for reduction. This is higher than reported in prior studies of sub-tenon's triamcinolone monotherapy for macular edema secondary to retinal vein occlusions [7-9]. Due to the small sample size, however, it is unclear if the results would have been different if there was a larger patient sample. It is likely that these patients should have normalization of the IOP with the gradual steroid depot reduction and use of topical IOP drops, but these patients will now require even closer monitoring of this parameter in addition to visual field and retinal nerve fiber layer studies.

\section{Conclusions}

Simultaneous same day anti-VEGF and sub-tenon's acetonide injections can help to reduce macular edema associated with central retinal vein occlusions and help to lengthen the interval between anti-VEGF injections. This combination therapy was less successful at improving visual acuity in this small case series and two of four patients had an elevation of intraocular pressure at three months requiring ongoing topical IOP lowering therapy. Further 
research is needed to determine if prompt combination treatment for CRVO associated macular edema can improve visual acuity at three months and beyond.

\section{References}

1. Campochiaro PA, Wykoff CC, Brown DM, et al. Suprachoroidal triamcinolone acetonide for retinal vein occlusion: Results of the Tanzanite Study. Ophthalmology Retina 2 (2018): 320-328.

2. Moon J, Kim M, Sagong M. Combination therapy of intravitreal bevacizumab with single simultaneous posterior subtenon triamcinolone acetonide for macular edema due to branch retinal vein occlusion. Eye 30 (2016): 1084-1090.

3. Campochiaro PA, Heier JS, Feiner L, et al. Ranibizumab for macular edema following branch retinal vein occlusion: six-month primary end point results of a phase III study. Ophthalmology 117 (2010): 11011112.

4. Brown, DM, Campochiaro PA, Singh RP, et al. Ranibizumab for macular edema following central retinal vein occlusion: six-month primary end point results of a phase III study. Ophthalmology 117 (2010): 11241133.

5. Ip MS, Scott IU, VanVeldhuisen PC, et al. SCORE Study Research Group. Arch Ophthalmol 127 (2009): 1101-1014.

6. Ashraf M, Souka AAR. Review article: Steroids in central retinal vein occlusion: Is there a role in current treatment practice? Journal of Ophthalmology (2015): 1-7.

7. Kola M, Hacioglu D, Turk A, et al. The effectiveness and reliability of posterior sub-tenon triamcinolone acetonide injection in branch retinal vein occlusion-related macular edema. Journal Cutaneous and Ocular Toxicology 35 (2016): 185-189.

8. Tran VH, Ambresin A, Wolfensberger TJ. Posterior sub-tenon triamcinolone injection for macular edema associated with retinal vein occlusion. Investigate Ophthalmology and Visual Science (2007): 1548.

9. Gurram MM. Effect of posterior sub-tenon triamcinolone in macular edema due to non-ischemic vein occlusions. Journal of Clinical and Diagnostic Research 7 (2013): 2821-2124.

Citation: Justin J. Yamanuha, Carolyn R. Flock. Same Day Sub-tenon's Triamcinolone and Anti-VEGF Injections in Patients with Macular Edema Secondary to Central Retinal Vein Occlusion. Archives of Clinical and Medical Case Reports 2 (2018): 245-253.

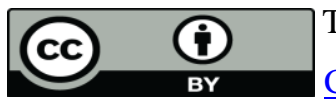

This article is an open access article distributed under the terms and conditions of the

$\underline{\text { Creative Commons Attribution (CC-BY) license 4.0 }}$ 